\title{
A presença da literatura nos "argumentos" de Schopenhauer a favor da primazia da vontade sobre o intelecto
}

\author{
The presence of literature in Schopenhauer's "arguments" about the \\ primacy of the will over the intellect
}

\author{
Vilmar Debona \\ Professor do Programa de Pós-Graduação em Filosofia da UFRRJ \\ Coordenador do GT-Schopenhauer da ANPOF \\ E-mail: debonavilmar@gmail.com
}

\begin{abstract}
Resumo: Este pequeno artigo investiga a presença de alguns dos clássicos da literatura universal nos argumentos e provas de Schopenhauer a favor da primazia da vontade sobre o intelecto. Enfatizamos que, além de ter considerado como ratificadoras de seu pensamento as ciências naturais que vieram à lume ulteriormente à elaboração da sua metafísica da vontade, o pensador também insistiu que as teses centrais da sua filosofia teriam como chancela a produção artística e literária de grandes nomes. 0 texto apresenta, em específico, um breve mapeamento dos principais literatos que o filósofo cita no capítulo 19 do Tomo II de $O$ mundo como vontade e representação, intitulado justamente Do primado da vontade na consciência de si, para corroborar suas afirmações. Isso não retira o pretendido caráter propedêutico do artigo, que visa uma abordagem horizontal - e não vertical - da vasta temática sobre o uso da literatura feito por Schopenhauer.
\end{abstract}

Palavras-chave: Primado da vontade; Intelecto; Literatura universal.
Abstract: This short article investigates the presence of some classics of world literature In Schopenhauer's arguments and evidences about the primacy of the will over the intellect. We emphasize that in addition to having contemplated as ratifiers of his thought the natural sciences that came to light later than the elaboration of his metaphysics of will, the thinker also insisted that the central thesis of his philosophy would have sanctioned the artistic and literary production of relevant minds. The text presents a succinct summary of the main writers that the philosopher quotes in chapter 19 of volume II of The world as will and representation, precisely titled The primacy of the will in self-consciouness, to support their claims. This text does not remove the intended propaedeutic character of the article, which aims a horizontal rather than a vertical approach of wide use of literature that was did by Schopenhauer in his works.

Keywords: Primacy of the will; Intellect; World literature. 
É muito conhecida a crítica voraz que Schopenhauer dirige a alguns de seus contemporâneos quanto à falta de materialidade, realidade e efetividade de suas filosofias. "Emaranhados vazios de palavras", "enormes acumulações verbais que nada dizem", "lento suplício de boatos ocos, fúteis", "filisteria sistematizada" são algumas das expressões endereçadas a Fichte, a Schelling e a Hegel devido ao obscurantismo de suas doutrinas da intuição intelectual e do espírito absoluto, cujos nomes mais corretos seriam, aos olhos do filósofo da vontade, "vazio intelectual e charlatanismo"2. De forma semelhante, "bolhas de sabão apriorísticas", "cascas sem caroço" e "teia de aranha de conceitos, os mais sutis e vazios de conteúdo"3 é como ele se refere ao fundamento e ao princípio dados à moral por Kant. Esta crítica é vasta, está presente em diversos momentos nos quais o filósofo trata de assuntos também variados, e geralmente é seguida pela insistência típica de Schopenhauer em indicar ao leitor que a veracidade de seu pensamento pode ser, de alguma forma, atestada e comprovada pela efetividade de suas intuições e até mesmo pela clareza de sua escrita.

Há ocasiões em que o pensador salienta a exigência de realidade e de materialidade de sua filosofia, como no início do Livro IV do tomo I de 0 mundo como vontade e como representação, ao abordar pela primeira vez de forma sistemática a fundação metafísica da ética.

Nossa tarefa filosófica só pode ir até a interpretação e a explanação do agir humano e de suas diversas (e até mesmo opostas) máximas [...]. Nossa filosofia afirmará aqui a mesma imanência afirmada em tudo o que foi antes discutido. Não usará, e assim respeita a grande doutrina de Kant, as formas do fenômeno, cuja expressão geral é o princípio de razão, como uma vara de saltar para sobrevoar o fenômeno, único a lhes conferir significação, e depois pousar no vasto domínio das ficções vazias. Este mundo efetivo da cognoscibilidade, no qual estamos e que está em nós, permanece como matéria e limite de nossa consideração. Mundo tão rico em conteúdo que nem a mais profunda investigação da qual o espírito humano é capaz poderia esgotá-lo. Ora, visto que o mundo efetivo e cognoscível jamais recusará matéria e realidade (Stoff und Realität) também para nossas considerações éticas, tampouco quanto o recusou para as considerações anteriores, nada será menos necessário do que procurarmos refúgio em conceitos negativos e vazios de conteúdo $[\ldots]^{4}$.

\footnotetext{
${ }^{1}$ Cf. SCHOPENHAUER, A. N, p. 27.

2 SCHOPENHAUER, A. MVR I, Prefácio à segunda edição, p. 30.

3 Cf. SCHOPENHAUER, A. M, p. 53.

${ }^{4}$ SCHOPENHAUER, A. MVR I, § 53, p. 355, grifos do autor.

A presença da literatura nos "argumentos" de Schopenhauer a favor da primazia da vontade sobre o intelecto
} 
Há outras ocasiões em que Schopenhauer indica a coincidência de sua metafísica imanente da vontade com descobertas científicas ulteriores, como em Sobre a vontade na natureza, no prefácio à segunda edição (1854), onde afirma que cientistas "empíricos imparciais" (da fisiologia, anatomia comparada, astronomia, linguística, magnetismo animal, magia e sinologia), desconhecedores da metafísica da vontade, descobriram, no final das contas, o mesmo que sua doutrina havia estabelecido como o metafísico, o que haveria de servir como fator que distingue o seu pensamento de todos os anteriores, já que estes teriam deixado um abismo entre seus resultados e a experiência. Já no seu caso, seria possível atestar que a metafísica da vontade

mantém-se como a única que possui efetivamente uma fronteira comum com as ciências físicas, um ponto no qual estas, por meios próprios, vão ao seu encontro, de modo que elas realmente se encadeiam com ela e com ela concordam [...] Ambas encontram-se no mesmo ponto por conta própria e sem combinação prévia. Daí segue que meu sistema não flutua no ar como todos os anteriores, acima de toda realidade e experiência; pelo contrário, ele descende até esse chão firme de efetividade $[\ldots]^{5}$.

Mas em relação a que tese ou pensamento Schopenhauer pretende dar garantia de não ter deixado o abismo entre resultado e experiência que acusa nos outros? Em primeira instância, diz ele, em relação "ao cerne e ao ponto central de minha doutrina, à verdadeira metafísica desta, isto é [...] àquilo que encontramos dentro de nosso próprio eu como vontade"6, ou seja, em relação ao estofo primordial de seu pensamento. Em termos mais específicos, àquilo que o filósofo, em um fragmento póstumo de 1826, chamou de seu "dogma principal" (Hauptdogma)7 e, em uma carta ao discípulo Frauenstädt, de 06 de junho de 1856, definiu como "a mais importante de todas as verdades" (die wichtigste aller Wahrheiten) ${ }^{8}$, a saber, o primado da vontade sobre o intelecto, núcleo fundante de todo o seu sistema, ou seja, a tese repetida à exaustão de que "a vontade, como coisa em si, constitui a íntima, verdadeira e indestrutível essência do ser humano"9 ${ }^{9}$ que, porém, em si mesma é sem consciência, já que tal consciência "é

\footnotetext{
5 SCHOPENHAUER, A. N, p. 43-44.

6 Idem, ibidem.

7 "Ein Hauptdogma bei mir ist der Primat des Willens über den Intellekt im Menschen" (SCHOPENHAUER, A. HN, Quartant, § 134, p. 255, grifos do autor).

8 SCHOPENHAUER, A. Briefwechsel, XV, carta a Julius Frauenstädt, Frankfurt a. M., 6. Juni 1856, p. 491-492.

${ }^{9}$ SCHOPENHUAER, A. MVR II, cap. 19, p. 243.

A presença da literatura nos "argumentos" de Schopenhauer a favor da primazia da vontade sobre o intelecto
} 
condicionada pelo intelecto, e este é um mero acidente do nosso ser"10. De forma resumida, trata-se da defesa de que se a vontade é metafísica, o intelecto é físico; se a vontade é a coisa em si, o intelecto é a simples aparência; se a vontade é a substância, o intelecto é o acidente; se a vontade é a matéria, o intelecto é a forma; se a vontade é o calor, o intelecto é a luz ${ }^{11}$. Algumas alegorias ilustram esta tese com uma vivacidade única, como (1) a alegoria das plantas: "Estas [as plantas] têm, como sabido, dois polos, raiz e corola: a primeira esforçando-se por escuridão, umidade, frio, a segunda por luminosidade, sequidão, calor [...]. A raiz é o essencial, originário, perdurável, cuja morte atrai para si a da corola, é, portanto, o primário; a corola, ao contrário, é o ostensivo [...], o secundário"12; (2) a alegoria que compara o cansaço dos braços após prolongado trabalho com a fadiga do cérebro após prolongado esforço da cabeça, sem que, porém, isso implique num cansaço do querer, fato que explicaria que o intelecto se cansa, mas a vontade é incansável13; e (3) a alegoria de um cego forte (ilustração da vontade) que carrega nos ombros um paralítico que enxerga (ilustração do intelecto) ${ }^{14}$.

Foi para corroborar este seu pensamento, a defesa da primazia da vontade sobre o intelecto ou a consciência de si, que Schopenhauer empreendeu uma infatigável busca pelo o que chamou de "argumentos" (Argumente), "confirmações empíricas" (empirischen Bestätigungen) ou "fatos" (Thatsachen).

Principalmente a partir de 1826, o filósofo começou a reunir de forma sistemática um corolário expressivo de confirmações que, conforme verificamos nos Nachlass, em 1840 já somavam 106 argumentos, uma série que o autor não considerava encerrada. No livro dos Quartant, ao iniciar esta série de 106 argumentos, Schopenhauer anota à margem do caderno o que a sua pena passaria a registrar nos próximos quatorze anos: "provas (Belege) da absoluta diferença da vontade em relação ao intelecto e do primado daquela sobre este". E, ainda: "Dado que o pensamento de fundo é somente um, as explicações aqui propostas carecem do estímulo da variedade, mas são importantes para uma compreensão aprofundada da verdade fundamental da minha filosofia"15. As formulações de tais 106 "explicações" encontram-se espalhadas por nove livros dos

10 Idem, ibidem.

11 Cf. idem, p. 244.

12 Idem, p. 245.

${ }^{13}$ Cf. idem, p. 255.

${ }^{14}$ Cf. idem, p. 253.

15 SCHOPENHAUER, A. HN, Quartant, § 134, p. 255, grifos do autor.

A presença da literatura nos "argumentos" de Schopenhauer a favor da primazia da vontade sobre o intelecto 
Volumes III e IV dos Manuscritos póstumos ${ }^{16}$, mesmo que tudo leve a supor que o filósofo as tenha reelaborado e sintetizado para serem publicadas no capítulo 19 do tomo II da obra magna.

Como se sabe, neste capítulo 19 (de 1844), cujo título é justamente Do primado da vontade na consciência de si ${ }^{17}$, Schopenhauer enumerou 12 tópicos sobre o assunto dos argumentos comprobatórios da primazia da vontade. Ao iniciar este elenco, o autor afirma: "Queremos agora, em primeiro lugar, documentar (dokumentiren), e ao mesmo tempo explicitar essa tese mediante os seguintes fatos (Thatsachen) pertencentes à vida interior do ser humano"18. 0 emprego da palavra "prova", nos Manuscritos de 1826, e da palavra "fato", nos Suplementos de $O$ mundo de 1844, parece indicar suficientemente a busca por algum tipo de demonstração que, neste caso, por tomar como fonte a "vida interior do homem", mescla fatos empírico-psicológicos com provas caracterológicas e literárias, o que permitirá ao pensador formular um vasto campo de saber antropológico e psicológico, ou então, o que ele também chamou de "mera psicologia empírica" (bloße empirische Psychologie) ${ }^{19}$. Aliás, será a partir desse significativo material que o pensador reivindicará o epíteto de primeiro filósofo a proclamar a onipotência da vontade e a natureza secundária e acidental do intelecto ${ }^{20}$, o que acabou lhe rendendo uma forma de protagonismo quanto à abertura da filosofia à contemporaneidade.

Ora, às mencionadas descobertas científicas, que surgiram após a formulação da metafísica da vontade e estariam destinadas a comprová-la, somam-se "argumentos" não só do âmbito da antropologia e da psicologia empírica, mas da literatura, como espécie de atestado de pontos nodais dessa filosofia. Com efeito, é bastante conhecido o gosto de

\footnotetext{
160 elenco desses 106 argumentos que aparecem nos Póstumos de forma descontínua, mas enumerados pelo autor, é o seguinte: No volume III: Quartant, § 134, pp. 255-258 [Argumentos 1-11]; Foliant II, § 204, pp. 332-335 [Argumentos 12-16]; Adversaria, § 37, pp. 427-436 [Argumentos 17 e 18]; Adversaria, § 83, pp. 505-511 [Argumentos 19-25]; Adversaria, § 228, pp. 506-513 [Argumentos 26-40]. No volume IV: Cogitata I, § 54, pp. 24-31 [Argumentos 41-49]; Cogitata I, § 114, pp. 68-71 [Argumentos 50-55]; Cogitata II, § 136, pp. 133-138 [Argumentos 56-66]; Cholera-Buch, § 2, pp. $72-75$ [Argumentos 67 e 68]; CholeraBuch, § 30, pp. 90-94 [Argumentos 69-75]; Pandectae I, § 4, pp. 112-118 [Argumentos 76-89]; Pandectae II, § 87, pp. 181-187 [Argumentos 89b-103]; e Spicilegia, § 53, pp. 260-261 [Argumentos 104-106] (Cf. SCHOPENHAUER, A. HN, Vols. III e IV).

17 No original, Vom Primat des Willens im Selbstbewußtseyn. As duas traduções brasileiras do Tomo II de $O$ mundo de que dispomos apresentam traduções diferentes para o termo Selbstbewußtseyn. Eduardo Ribeiro da Fonseca o traduz por "autoconsciência” e Jair Barboza o verte por "consciência de si".

18 SCHOPENHAUER, A. MVR II, cap. 19, p. 244.

19 Cf. SCHOPENHAUER, A. P II, Sobre a filosofia e seu método, § 21, p. 49.

20 Cf., por exemplo, SCHOPENHAUER, A. Briefwechsel. Carta a Julius Frauenstädt, Frankfurt a. M., 6. Juni 1856, p. 492.

A presença da literatura nos "argumentos" de Schopenhauer a favor da primazia da vontade sobre o intelecto
} 
Schopenhauer em invocar autoridades da literatura universal ${ }^{21}$ para justificar teses centrais de seu pensamento.

No entanto, como poderia a literatura - enquanto arte - ter condições de corroborar a metafísica da vontade ou a primazia da vontade, apresentando-se como uma espécie de segunda ordem de chancela, ao lado daquela oferecida pelas ciências empíricas? A pergunta aduz diretamente à superioridade que a arte possui no pensamento schopenhaueriano em relação à ciência, algo que o filósofo estabelece principalmente no âmbito de sua metafísica do belo. Com efeito, podemos ler nas Preleções sobre a Metafísica do belo uma passagem que daria conta da questão: seguindo o princípio de razão, afirma o pensador,

as ciências procuram tornar tudo concebível enquanto consequência de um fundamento, tentam fornecer para tudo um porquê, uma resposta [...]. [Já a arte] retira o objeto de sua contemplação da torrente do curso do mundo e o isola diante de si; e esse particular, que era na torrente fugidia uma parte ínfima a desaparecer, torna-se um representante do todo [...]. A arte se detém nesse particular, a roda do tempo para; as relações desaparecem para ela. Apenas o essencial, a Ideia, é seu objeto $^{22}$

Ou seja, a arte, por ter como objeto o essencial do mundo (objeto este que varia de acordo com o grau de manifestação da vontade na natureza) seria superior em relação à ciência quando se trata de "dizer" o mundo, uma vez que as ciências se restringem ao transitório das aparências e estão limitadas às formas do princípio de razão. Sendo assim, poderíamos supor que o uso da literatura (como expressão artística) feito por Schopenhauer enquanto forma de chancelar a primazia da vontade seria também superior à ciência conquanto esta última é usada para a mesma finalidade; de modo que, talvez, não seria desarrazoado conceber que Schopenhauer ofereceu a si próprio a legitimidade para escrever não apenas um livro sobre a vontade na natureza, como, de fato o fez, mas também um outro sobre "a vontade na literatura", que poderia ter escrito. Se, para tanto, ele tivesse dependido da variedade de literatos que usou a seu favor, o intento não seria dificultado. De fato, a literatura comparece de forma vasta e

210 termo "literatura" é empregado aqui no sentido de arte literária, do uso estético da linguagem escrita ou de obras literárias de reconhecido valor estético que pertencem a determinada época, lugar ou gênero. 22 SCHOPENHAUER, A. MB, p. 58-59. 
multifacetada na quase totalidade das teses da sua filosofia ${ }^{23}$.

Tenhamos presente, de início, alguns exemplos conhecidos que podem ser localizados sem dificuldades na sua obra em geral: 1) No $§ 59$ de $O$ mundo (tomo I), um dos trechos mais pessimistas de toda a sua obra, o filósofo recorre a William Shakespeare (1564-1616) ${ }^{24}$ e ao famoso monólogo de seu Hamlet ${ }^{25}$ para explicar a condição miserável do homem e seu decurso de vida como uma série contínua de grandes e pequenos acidentes, num mundo em que o preferível seria a completa nãoexistência. 2) Neste mesmo parágrafo, Dante Alighieri (1265-1321)²6 também é invocado para a argumentação da natureza do próprio mundo a partir da facilidade com que o florentino extraiu matéria para seu Inferno, ordenando-o corretamente, ao contrário do que acontece no caso do seu Paraíso. 3) Impossível não lembrar também de outra presença literária no âmago da acepção schopenhaueriana que toma toda a vida como dor e sofrimento, a saber, de Calderón de la Barca (1600-1681), de quem Schopenhauer emprestaria a conhecida "el delito mayor del hombre es haber nacido", de seu La vida es sueño. 4) Já no $§ 14$ da dissertação Sobre o fundamento da moral, quando o pensador termina a revista das motivações antimorais das ações humanas, é a vez de John Milton (1608-1674) se fazer presente para que as referidas potências antimorais pudessem ser equiparadas ao príncipe das trevas no Pandemônio do poeta inglês ${ }^{27}$. Isto para não mencionarmos a profusa presença do conterrâneo Goethe em quase todo o corpus filosófico do pensador, e, ainda, a insólita referência à literatura sânscrita.

Na esfera específica aqui analisada, a dos argumentos a favor do primado da vontade sobre o intelecto, o uso dessa literatura não é menos significativo. Uma análise do referido cap. 19 do tomo II de $O$ mundo, ocasião em que aparecem os 12 referidos argumentos (possível síntese dos 106 encontrados nos Póstumos), pode revelar o quão

\footnotetext{
${ }^{23}$ É importante notar que, mesmo sendo vasta a presença da literatura no pensamento de Schopenhauer, ainda não contamos com muitos e significativos estudos no âmbito da Schopenhauer-Forschung internacional sobre a natureza e as formas do influxo dos grandes literatos nesta filosofia, com exceção daqueles sobre Goethe. Mesmo os anuários da Schopenhauer-Gesellschaft, em seus mais de cem anos de existência, publicaram poucos trabalhos sobre esse tema variegado, com uma considerável diferença em relação a quando se trata das presenças ou influências de Schopenhauer em grandes nomes da literatura ou das artes.

${ }^{24}$ Sobre alguns aspectos da presença de Shakespeare em Schopenhauer, ver o excelente capítulo de Tom Stern intitulado Schopenhauer's Shakespeare: the genius on the world stage, publicado recentemente na coletânea Shakespeare and Continental Philosophy. Pela Edinburgh University Press, pp. 56-75.

${ }^{25}$ Cf. SCHOPENHAUER, A. MVR I, § 59, p. 417.

${ }^{26}$ Cf. idem, p. 418.

27 Cf. SCHOPENHAUER, A. M, § 14, p. 127.

A presença da literatura nos "argumentos" de Schopenhauer a favor da primazia da vontade sobre o intelecto
} 
relevante é a presença de clássicos da literatura universal para fins da mencionada "documentação" do "dogma principal" schopenhaueriano. Para notarmos isso de modo mais específico, façamos, pois, um breve percurso pelo interior de alguns dos tópicos enumerados por Schopenhauer neste capítulo 19.

No argumento $\mathrm{n}^{\mathrm{0}}$ 5, ao tomar a vontade como o real e o essencial no ser humano e apontar o intelecto como secundário, condicionado e gerado, o filósofo infere que isso seria testado pelo fato de que

[o intelecto] só pode desempenhar de forma pura e correta a sua função pelo tempo em que a vontade silencia e faz pausa; por outro lado, a função do intelecto é perturbada através de cada estímulo observável da vontade que, por sua interferência, falseia os resultados dele: o inverso não se observa, ou seja, que o intelecto seja de maneira semelhante um empecilho à vontade. Assim, a lua não pode fazer efeito quando o sol está no céu; de fato, não é empecilho para este ${ }^{28}$.

Ora, para explicitar esse argumento, Schopenhauer recorre a um gigante da literatura cuja presença é notável também em textos anteriores e posteriores à elaboração desse cap. 19, a saber, ao espanhol Baltasar Gracián (1601-1658), de quem o filósofo assegura ter lido todas abras, sendo o Criticón "um dos livros que mais amo no mundo"29. 0 jesuíta barroco, como sabemos, mereceria de Schopenhauer uma tradução para o alemão (cuja versão completa foi publicada em 1862, por Brockhaus) de seu Oráculo Manual e Arte da prudência (1647) ${ }^{30}$. Dentre outras ocasiões em que é citado, no $\S 50$ de $O$ mundo, Gracián se faz presente com seu Criticón, obra tomada, ali, ao lado de Dom Quixote, de Miguel de Cervantes (1547-1616), e das Viagens de Gulliver, de Jonathan Swift (1667-1745), como "três obras alegóricas de grande fôlego". No contexto do tema da primazia da vontade sobre a consciência de si, especificamente, a autoridade gracianiana se faz presente como argumento literário para atestar a constatação de que o intelecto só pode desempenhar alguma função de forma correta enquanto a vontade estiver aquietada e, para tanto, a formulação é extraída de Discreto (X, 365b): "la passion

\footnotetext{
${ }^{28}$ SCHOPENHAUER, A. MVR II, cap. 19, p. 260.

${ }^{29}$ Cf. SCHOPENHAUER, A. Briefwechsel, XV, carta a Johann Georg Keil, Frankfurt a. M., 16. April 1832. Cf., também, BRUM, J. T. O legado espanhol - Calderón e Gracián inspiradores de Schopenhauer, pp. 115-120.

30 Em especial na Espanha, há uma produção considerável sobre a presença e a influência de Gracián em Schopenhauer. Restrinjo-me a mencionar alguns trabalhos, como o de José Luis Losada Palenzuela, Schopenhauer traductor de Gracián. Diálogo y formación, 2011; o de Jiménez Moreno, Presencia de B. Gracián en filósofos alemanes: Schopenhauer y Nietzsche, 1993; o de Elena Cantarino, Gracián y Schopenhauer. La gran sindéresis o "die grosse Obhut seiner selbst", 2011; e o de Juan David Mateo Alonso, Schopenhauer y Gracián: arte de prudencia y sabiduría mundana, 2013. 
es enemiga declarada de la cordura, a paixão é inimiga declarada da prudência" ${ }^{31}$. 0 poderio da vontade sobre o intelecto se manifestaria, assim, porque a paixão não obedece à consciência, mas ao afeto. Se o intelecto não fosse diferente da vontade, com a excitação e a intensificação desta última (via intensificação do afeto), também ele teria que se intensificar. Mas a realidade diz o contrário: quando a vontade é excitada, o intelecto resta entorpecido e deprimido, o que parece adaptar muito bem o espírito da formulação de Gracián no horizonte da metafísica da vontade.

Um pouco adiante, ainda no argumento 5, é outra suma autoridade da literatura que comparece, desta vez Lord Byron (1788-1824). Trata-se da ocasião em que Schopenhauer observa como o influxo perturbador da vontade sobre o intelecto não se mostra apenas nos afetos, o que se pode observar no fato de que, segundo ele,

a essência da esperança reside em que a vontade, quando seu servo, o intelecto, não é capaz de fornecer o objeto desejado, obriga-o ao menos a pintá-lo e a em geral assumir o papel de consolador, apaziguando desse modo o seu senhor como a ama o faz com a criança ao narrar-lhe contos de fada [..]; com isso o intelecto tem de fazer violência à própria natureza, na medida em que é compelido, contrário a suas leis, a tomar por verdadeiras coisas que não são verdadeiras, nem prováveis, e amiúde raramente são possíveis - tudo isso em vista de apaziguar, acalmar e fazer dormir por instantes a inquieta e indômita vontade. Aqui vê-se claramente quem é senhor e quem é servo ${ }^{32}$.

Byron, amplamente citado pelo filósofo, como nos $\S \S 34$ e 51 do tomo I e no capítulo sobre o gênio (31) do tomo II de $O$ mundo 33 , é aqui invocado por Schopenhauer

\footnotetext{
${ }^{31}$ SCHOPENHAUER, A. MVR II, cap. 19, p. 261.

32 Idem, p. 262.

33 Podemos mensurar o apreço de Schopenhauer por Byron quando lemos o protesto que o pensador faz nos Parerga e paralipomena sobre a proibição de se fixar uma estátua do poeta na famosa abadia de Westminster: "A influência dos padres na Inglaterra é tão grande que, para a vergonha da nação inglesa, o monumento feito por Thorwaldsen a Byron, o seu maior poeta depois do inatingível Shakespeare, não pôde ser fixado na abadia de Westminster, ao lado dos outros grandes homens do pantheon nacional inglês [...]. Uma futura e melhor geração haverá de levar com pompa a estátua de Byron à igreja de Westminster" (SCHOPENHAUER, A. P, I, Versuch über Geistersehn und was damit zusammenhängt, p. 301302). Há outras várias ocasiões em que Byron é citado por Schopenhauer, como no cap. 46 do tomo II de $O$ mundo, ao lado de Shakespeare e do poeta italiano Leopardi, este que também era conhecido com profundidade (embora não pessoalmente) pelo filósofo. Curioso é notar, aliás, que, no relato de uma conversa pessoal com Schopenhauer, Robert von Hornstein registra as seguintes palavras do filósofo de Frankfurt: "Sabias que na Itália, num mesmo ano, estiveram os três maiores pessimistas? Foi algo detectado por [Adam von] Doß: Byron, Leopardi e eu" (cf. SCHOPENHAUER, A. Gespräche, trad. it., p. 159). A menção de Schopenhauer a Doß na conversa com R. v. Hornstein refere-se ao que havia escrito o próprio Doß numa carta ao filósofo (cf. SCHOPENHAUER, A. Briefwechsel, XV, carta de Adam von Doß a Schopenhauer, München, 20 Februar 1858, p. 613). Sobre este último assunto e também sobre a recepção A presença da literatura nos "argumentos" de Schopenhauer a favor da primazia da vontade sobre o intelecto
} 
mediante um verso da obra poética Lara (canto I, XXVIII). O pequeno trecho citado pelo filósofo é o seguinte: "Algo que reconhecemos como falso, contudo tememos seriamente, / Porque o pior sempre está mais próximo da verdade" ${ }^{34}$. Diríamos, assim, que por exigência e ordem da vontade, o serviçal intelecto teria de admitir que mesmo a evidência da falsidade de algo - ocasionalmente tida como objetiva e segura - não é suficiente para convencer a vontade, exteriorizada no verso de Byron pelo temor, de que o pior é impossível. E já que não possui força suficiente para um tal convencimento da vontade, o intelecto se obriga, então, não apenas a imaginar ou supor que mesmo algo falso pode vir a acontecer, mas também a ceder ao temor de que tal coisa aconteça.

No argumento $\mathrm{n}^{\mathrm{o}}$ 8, Schopenhauer trata das propriedades individuais: de um lado, ele aborda os méritos e defeitos da vontade e do caráter; do outro, os méritos e defeitos do intelecto. Esta é a ocasião em que o filósofo argumenta, p. ex., que se, por um lado, "a carência de entendimento de modo algum é favorável ou aparentada à bondade de caráter", por outro lado "não se pode afirmar que o grande entendimento seja assim: antes, sem este, jamais existiu um facínora. Inclusive, até mesmo a mais elevada eminência intelectual pode coexistir com a pior das depravações morais" ${ }^{35}$. Para ilustrar esta hipótese, o filósofo cita alguns exemplos históricos e, mais uma vez, recorre à literatura para mencionar, desta feita, o relato que o escritor, historiador e romancista Giovanni Rosini (1776-1855) faz sobre o também escritor, historiador e político italiano Francesco Guicciardini (1483-1540), em suas Notizie storiche, espécie de apêndice da obra Luisa Strozzi: storia del secolo XVI: "Aqueles que põem o engenho e o saber acima de todas as outras humanas qualidades, computarão este homem [Guicciardini] entre os maiores do seu século: mas aqueles que consideram que a virtude deve preceder a tudo o mais, não conseguirão amaldiçoar o suficiente a sua memória. Foi o mais cruel dos cidadãos em perseguir, matar e confinar" ${ }^{36}$. E conclui disso uma possível explicação sobre porquê quando se diz de uma pessoa que "ela tem um bom coração, mas uma cabeça ruim", o louvor ultrapassa em muito a censura, enquanto que quando se diz que "ela tem uma cabeça muito boa, mas um coração ruim", ocorre o contrário.

No argumento $\mathrm{n}^{\mathrm{o}}$ 9, após elencar uma variedade de expressões em diversas

de Byron por Schopenhauer, cf. DE LORENZO, G. Schopenhauer, Byron e Leopardi. Schopenhauer-Jahrbuch, pp. 97-104).

34 SCHOPENHAUER, A. MVR II, cap. 19, p. 263.

35 Idem, p. 276.

36 Idem, p. 277. A referência da obra de Rosini citada por Schopenhauer é: Luisa Strozzi: storia del secolo XVI. Tomo IV. Pisa: Dalla Tipografia di N. Capurro e Comp., 1833, p. 230.

A presença da literatura nos "argumentos" de Schopenhauer a favor da primazia da vontade sobre o intelecto 
línguas sobre as diferenças entre o coração e a cabeça, e novamente citar Byron em seu Don Juan (c. 11, v. 34) sobre uma sátira feita por este ao afirmar que para as damas o amor é coisa da cabeça em vez do coração, Schopenhauer não deixa de recorrer a um fato ainda mais concreto que aqueles espelhados pela arte literária em vista de documentar que "a cabeça é sempre a segunda, a derivada": "quando um herói morre, embalsama-se o seu coração, não o cérebro: ao contrário, conserva-se de bom grado os crânios dos poetas, artistas e filósofos. Assim, o crânio de Rafael foi conservado na Academia di S. Luca em Roma [...], no ano de 1820, o crânio de Descartes foi vendido em leilão público na cidade de Estocolmo"37.

Mesmo que esta seja apenas uma visão parcial da presença de grandes nomes da literatura no âmbito dos argumentos schopenhauerianos sobre o primado da vontade, fácil é notar o quão Schopenhauer levou a sério, mediante seu apreço pela literatura, o cuidado para não incorrer naquele mesmo "abismo entre resultados e experiência" que acusara em alguns de seus contemporâneos. Se as diversas ciências naturais em Sobre a vontade na natureza seriam comprovações empíricas e efetivas do dogma principal desse pensamento em termos científicos, a literatura universal colhida nos numerosos argumentos sobre a primazia da vontade teriam documentado essa mesma verdade filosófica em termos literários. Tratar-se-iam, então, de duas formas distintas para se "provar" a mesma tese: uma que empresta argumentos das descobertas das ciências naturais, portanto, do mundo externo ao homem; outra que sai à procura da chancela da literatura como meio de expressão de fatos da vida interior do ser humano. Ou seja, provas ou fatos científicos, por um lado, e provas ou fatos psicológico-literários por outro. Neste último caso, porém, diferentemente do que havia dito em Sobre a vontade na natureza sobre o suposto caráter também comprobatório das ciências naturais, não se tratariam de atestados que se apresentaram por conta própria e sem combinação prévia, mas a partir do esforço que o próprio autor despendeu para buscar em obras clássicas de escritores, poetas, literatos etc elementos que funcionariam como chancela de seu pensamento. Para exagerar, aqui valeria ainda mais a metáfora formulada por Gabriel Valladão Silva na Apresentação à sua tradução brasileira de Sobre a vontade na

${ }^{37}$ SCHOPENHAUER, A. MVR II, cap. 19, p. 287-288. 0 filósofo cita a fonte da notícia como: “The Times, 18 out. 1845; segundo o Athenaeum".

A presença da literatura nos "argumentos" de Schopenhauer a favor da primazia da vontade sobre o intelecto 
natureza: se Schopenhauer teria mirado o horizonte das ciências naturais em busca de recrutas para o seu exército, esse "alistamento militar" 38 valeria ainda mais no plano da literatura, pois nesta última esfera a metafísica da vontade seria chancelada de forma deliberada, diferentemente do que teria ocorrido no primeiro caso, cujas confirmações científicas teriam se dado sem combinação prévia.

De uma forma ou de outra, se Schopenhauer chama a sua tese da primazia da vontade sobre o intelecto de seu "dogma fundamental", tratar-se-ia, por certo, de um "dogma" que se deixa experienciar, tamanha a variedade de argumentos que o atestam na empiricidade. Mas a expressão mais adequada para este tipo de dogmatismo seria dogmatismo imanente, conforme salientou Maria Lúcia Cacciola ${ }^{39}$ e o próprio filósofo observou: “[...] poder-se-ia chamar meu sistema de dogmatismo imanente, pois, embora seus princípios doutrinais sejam de fato dogmáticos, não ultrapassam todavia o mundo dado na experiência, mas apenas esclarecem o que ele é, já que o decompõe em suas partes componentes" 40 .

A peculiar metafísica schopenhaueriana, que só seria dogmática na medida em que fosse imanente, não incorreria nos "emaranhados vazios de palavras" que o autor acusara em seus contemporâneos porque teria sido expressa e, assim, atestada, pela literatura universal na medida em que esta é por ele considerada como espelho da vida e do mundo efetivos. Para essa finalidade teria Schopenhauer lançado mão de um Goethe, de um Byron, de um Shakespeare, de um Dante e de um Gracián etc, inflexões da filosofia que, de certa forma, seriam retribuídas pela literatura na posteridade por meio de um Thomas Mann, de um Tolstoi, de um Jorge Luis Borges e de um Machado de Assis, que, agora, lançariam mão do próprio Schopenhauer.

\section{Referências bibliográficas}

ALONSO, Juan David Mateo. Schopenhauer y Gracián: arte de prudencia y sabiduría mundana. ENDOXA. Series Filosóficas, Madrid, no 32, 2013, pp.63-87.

BRUM, José Thomaz. O legado espanhol - Calderón e Gracián inspiradores de Schopenhauer. In: SILVA, João Carlos Salles Pires da (Org.). Schopenhauer e o idealismo alemão. Salvador: Quarteto, 2004, pp. 115-120.

DE LORENZO, Giuseppe. Schopenhauer, Byron e Leopardi. Schopenhauer-Jahrbuch. Kiel, Bd. 4, 1915, pp. 97-104.

${ }^{38}$ Cf. SILVA, G. V. Sobre a verdade da natureza. In: SCHOPENHAUER, A. N, p. 19.

${ }^{39}$ Cf. CACCIOLA, M. L. Immanenter Dogmatismus, pp. 151-162.

40 SCHOPENHAUER, A. Fragmentos para a história da filosofia, p. 118.

A presença da literatura nos "argumentos" de Schopenhauer a favor da primazia da vontade sobre o intelecto 
CACCIOLA, Maria Lúcia. Immanenter Dogmatismus. Schopenhauer-Jahrbuch. Würzburg: Königshausen \& Neumann, Bd. 93, 2012, pp. 151-162.

CANTARINO, Elena. Gracián y Schopenhauer. La gran sindéresis o "die grosse Obhut seiner selbst". In: F. Oncina (Ed.). Schopenhauer en la historia de las ideas. Madrid: Plaza y Valdés, 2011.

JIMÉNEZ MORENO, L. Presencia de B. Gracián en filósofos alemanes: Schopenhauer y Nietzsche. In: J. Ayala (Ed.). Baltasar Gracián. Barcelona: Anthropos, 1993 (Suplemento, 37).

LOSADA PALENZUELA, José Luis. Schopenhauer traductor de Gracián. Diálogo y formación. Valladolid: Univ. de Valladolid, 2011.

ROSINI, Giovanni. Luisa Strozzi: storia del secolo XVI. Tomo IV. Pisa: Dalla Tipografia di N. Capurro e Comp., 1833.

SCHOPENHAUER, Arthur. Sämtliche Werke. Edição hitórico-crítica de Paul Deussen. 16 Bd. München: Piper Verlag. In: "Schopenhauer im Kontext III" - Werke, Vorlesungen, Nachlass und Briefwechsel auf CD-ROM (Release 1/2008), 1911-1941.

. Parerga und paralipomena. Tomo I. In: Sämtliche Werke. Bd. IV. München: Piper Verlag, 1911-1941.

. Der Handschriftliche Nachlass. In: Sämtliche Werke. Bd. XI. München: Piper Verlag, 19111941.

. Briefwechsel. In: Sämtliche Werke, Bd. XV. München: Piper Verlag, 1911-1941.

. Sobre o fundamento da moral. Trad. Maria Lúcia Cacciola. São Paulo: Martins Fontes, 2001.

. Fragmentos para a história da filosofia. Trad. Maria Lúcia Cacciola. São Paulo: Iluminuras, 2003.

. Metafísica do belo. Trad. Jair Barboza. São Paulo: Unesp, 2003. 2005.

O mundo como vontade e como representação. Tomo I. Trad. Jair Barboza. São Paulo: Unesp,

Parerga e paralipomena. Tomo II. Trad. Flamarion Caldeira Ramos (Capítulos 1 a 7). São Paulo: Hedra, 2010.

Colloqui (Gespräche). Prefazione, traduzione e commento di Anacleto Verrecchia. $3^{\underline{a}}$ ed. Milano: Bur Rizzoli, 2010.

Sobre a vontade na natureza. Tradução, prefácio e notas de Gabriel Valladão Silva. Porto Alegre: L\&PM, 2013.

O mundo como vontade e como representação. Tomo II. Trad. Jair Barboza. São Paulo: Unesp, 2015.

O mundo como vontade e representação. Tomo II. Trad. Eduardo Ribeiro da Fonseca. Curitiba: Editora UFPR, 2015.

SILVA, Gabriel Valladão. Sobre a verdade da natureza. In: SCHOPENHAUER, A. Sobre a vontade na natureza. Trad. Gabriel Valladão Silva. Porto Alegre: L\&PM, 2013, pp. 7-20.

STERN, Tom. Schopenhauer's Shakespeare: the genius on the world stage. In: Bates, Jennifer; Wilson, Richard (Eds.). Shakespeare and Continental Philosophy. Edinburgh: Edinburgh University Press, 2014, pp. 56-75.

Recebido: 04/10/16

Received: 10/04/16

Aprovado: $15 / 11 / 16$

Approved: 11/15/16

A presença da literatura nos "argumentos" de Schopenhauer a favor da primazia da vontade sobre o intelecto 